\title{
COGNITIVE FACTORS IN EPILEPSY
}

\author{
BY
}

\author{
MARGARET DAVIES-EYSENCK \\ From the Neurological Research Unit of the Medical Research Council, \\ National Hospital, Queen Square, London
}

A considerable number of studies has been carried out on cognitive aspects of epilepsy. Most of these have dealt with the general mental ability of the epileptic patient; for example, Sullivan and Gahagan's (1935) study in which of 103 epileptic children tested 14 were found to be mentally defective, the median I.Q. was 92, and I.Q.s ranged from 11 to 141 . Sheps (1947) has commented on the widely varied type of patient selected, and says, "This bias in the material is reflected in the wide variations of the results; for example there is a range in the reported mean I.Q.s of from 113.5 to 78." Sheps, studying the intelligence test results of the entire group of male epileptics of military age who were not in institutions for one military district in Canada from 1942 onwards, found their intelligence only slightly but significantly lower than that of the general population; the increase in the number of mental defectives in the epileptic group, $8.94 \%$ as against $7.29 \%$ in the total group of recruits, was not statistically significant. He points out that "most of the defective epileptics are institutionalized by the time they reach military age".

Other investigators have dealt with the general mental ability of epileptics more from the point of view of deterioration. Lennox (1944), quoting from his own findings in 1941 on a group of 1,640 clinic and private patients, states that

". . . 24\% were found to be abnormal during the first years of the disorder and $54 \%$ abnormal if the disease had persisted more than 25 years. There is progressive decrease in mentality with the total number of attacks, especially if these are psychomotor or grand mal or a combination of these. Cases with pure petit mal may go unscathed."

In addition a number of studies has been made to test directly the evidence for deterioration by giving groups of patients tests over a period of years. Lennox in commenting on these studies says, "Unfortunately the results are distorted by the fact that not all the original patients are followed throughout the period."
The further question of whether or not there are any special mental abilities in which the epileptic is inferior has not been overlooked. SomerfeldZiskind and Ziskind (1940) studying a group of 100 epileptic out-patients found memory retention and language ability somewhat defective. Arluck (1941), whose group numbered only 16 out-patients, reported results of the picture absurdity test being significantly worse in epileptics than in control groups. Lennox and Collins (1945) reported that epileptics who were given the Wechsler-Bellevue tests did relatively poorly in the performance tests. Capps (1939), who gave a number of word-meaning and usage tests to idiopathic epileptics, whose mental deterioration had been clinically estimated, found that " all of the vocabulary tests show a consistent, progressive and reliable tendency towards a reduction in the mean scores associated with the group of subjects showing the greater degree of mental deterioration." Patients on admission had an average I.Q. of 91.1 but on the Terman vocabulary test their I.Q. was only 53, and he concluded "Terman Vocabulary does not remain constant and unchanged with deterioration in idiopathic epilepsy and therefore cannot be employed to determine the native intellectual capacity of deteriorated epileptics."

All three approaches to cognitive aspects of epilepsy are followed in the investigations to be reported here. Data were collected and analysed in order to discover whether or not in general cognitive ability the epileptic patients would show a normal distribution; whether or not any tendency to deteriorate in cognitive ability would appear on re-testing two years later ; and whether or not, when compared with a control group, the epileptic patients would show any significant differences in such special mental abilities as memory, fluency, and vocabulary.

\section{Study of 161 Epileptic Patients}

Population.-One hundred and sixty-eight epileptic patients, children and young adults, attending an 
out-patient clinic at the National Hospital, London, were tested individually between June, 1945, and December, 1949. In most cases the testing was done within a few weeks of the patient's first attendance at the clinic. This in large measure circumvented the selection problem mentioned by Somerfeld-Ziskind and Ziskind (1940) that patients attending hospital out-patient departments may not fairly represent the whole group of epileptics living outside institutions, for those who are not helped by the treatment tend to drop out. In all 207 test batteries were administered, 39 being repeat tests. Of the 168 different patients, seven were too young for adequate measurement with the battery of tests used, reducing the number in the group to 161 . In 145 patients the medical diagnosis was "idiopathic" epilepsy ; in the remaining 16 the attacks were either known or suspected to have an organic basis. The attacks were of a minor character (petit mal) in 37 patients and either of a major (grand mal) or major and minor character in 124 patients.

Tests.-At the outset of the research it was known that the patients would vary greatly in age, so a battery of tests was designed which would enable an estimate of ability to be made from the age of 6 years up to adulthood. The following tests were used and after each are given the scores derived from them.

Cattell's (1936) Test of Retentivity (Memory).-Time allowed was one half minute for learning followed by one minute for recall for each of four parts : (1) page with 10 simple pictures; (2) 10 nonsense syllables (to be recognized later among 20) ; (3) 10 geometric shapes (to be recognized later among 20); (4) 10 words read slowly twice to subject. Two scores were made: the total number of items given correctly at immediate recall ; the total number given at delayed recall after roughly one hour's testing.

Progressive Matrices (Untimed Version).-Board form of sets A and B were used for 8-year-olds and younger. Three scores were made: (1) the total number of problems correct converted into percentiles and thence into I.Q.s ; (2) the time taken ; and (3) "scatter" on separate sets.

Fluency Tests.-These consisted of the number of names of flowers given in one minute, the number of names of birds given in one minute, the number of different items under a tree (Fig. 48 in Cattell's (1936) book), and the number of different items in a street (Fig. 49 in Cattell's book). Two scores were made : (1) reproductive fluency, i.e., the number of flowers plus the number of birds, and (2) imaginative fluency, the number of items under the tree plus the number of items in the street.

Mill Hill Vocabulary Test.-Both A and B forms for definitions were used. One score, the number of correct definitions given, assessed in accordance with acceptable responses kindly supplied by Raven, was converted into verbal attainment quotients (V.A.Q.) from norms given by Raven.

Results.-The interest in this first investigation lies mainly with the general mental ability of epileptic patients, measured by intelligence tests, and not with their special abilities or disabilities, measured by memory and fluency tests. Accordingly, the summary of results in this section will be confined to the progressive matrices and Mill Hill vocabulary tests.

Raven's five grades on these tests are based on percentiles, where Grade I equals I.Q. 124 and over ; Grade II equals I.Q. 110 to 123 ; Grade III equals I.Q. 91 to 109 ; Grade IV equals I.Q. 77 to 90 ; and Grade V equals I.Q. 76 and under. Each patient's percentile score was calculated and converted into an I.Q. Out of the group of 161 patients, 20 were below I.Q. 70 on progressive matrices and the same number below V.A.Q. 70 on vocabulary. Therefore, of this fairly representative group of epileptic patients, over $12 \%$ were mentally defective as measured by these tests. For the whole group the median I.Q., as assessed by the progressive matrices was 94, and the median V.A.Q., as assessed by the Mill Hill vocabulary test, was 96 .

Possibly of greater interest than these slightly under-normal medians for the epileptic group is the abnormal distribution of the matrices gradings. Table I shows the expected distribution of a normal population in the various grades and the distribution found for these 161 epileptics. The difference in distribution is statistically significant.

The group of epileptic patients has only a slightly below normal median I.Q., but the distribution of their gradings on the progressive matrices test differs significantly from a normal group. There are fewer patients with average scores $(27.9 \%$ as compared with the expected $50 \%$ ); a slightly

TABLE I

DISTRIBUTION OF EPILEPTIC PATIENTS' GRADING ON PROGRESSIVE MATRICES TEST COMPARED WITH NORMAL POPULATION

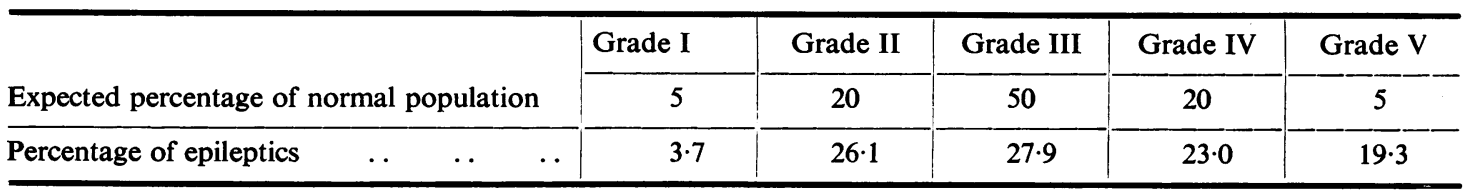


greater number above average $\left(29.8^{\circ} ;\right.$ as compared with the expected $25 \%$ ) ; and a great many more below average $(42 \cdot 3 \%$ as compared with $25 \%)$.

Intelligence quotients derived from the epileptic patients' scores on a non-verbal test, progressive matrices, and on a verbal test, Mill Hill vocabulary, are below the level of mental defect for over $12 \%$ of the group. This result confirms the findings of Sullivan and Gahagan (1935) who reported over $13 \%$ mentally defective in their group of 103 epileptic children.

\section{Re-test Results}

Population.-Thirty-nine children and young adults attending the Out-Patients' Clinic at the National Hospital, ranging in age from 5 to 19 years, with an average age of 11 , were given re-tests. The group included 20 girls and 19 boys, eight having minor attacks, 20 major attacks, 11 both minor and major attacks ; in one or possibly two patients the attacks had an organic origin, while in all the others they were considered to be idiopathic. grade on first testing and grade on second testing was $0 \cdot 76$.

Using the Mill Hill Vocabulary Test Raven's suggested working of the V.A.Q. as

$$
\text { verbal mental age }
$$

chronological age

was followed. The distribution curve is considerably flattened, at least for this particular group. The average V.A.Q. on first testing was $\mathbf{9 9 \cdot 2}$, and on second testing 95.4. It would be anticipated that the average V.A.Q. would be at least as high on the second testing if the vocabulary of the epileptics were growing at the normal rate. This considerable drop may find some partial explanation when the results are analysed further as below.

The V.A.Q.s were converted into grades for comparison with progressive matrices results. As with the matrices there is a great deal of individual variation in gradings on the two testings. The distribution curve is much flatter than for matrices so it might be expected that many more individuals would change from one grade to another : however,

TABLE II

RESULTS ON FIRST AND SECOND TESTING FOR PROGRESSIVE MATRICES AND MILL HILL VOCABULARY TESTS

\begin{tabular}{|c|c|c|c|c|c|}
\hline & & $\begin{array}{l}\text { Average I.Q. } \\
\text { 1st Testing }\end{array}$ & $\begin{array}{l}\text { Average I.Q. } \\
\text { 2nd Testing }\end{array}$ & $\begin{array}{l}\text { Average V.A.Q. } \\
\text { 1st Testing }\end{array}$ & $\begin{array}{l}\text { Average V.A.Q. } \\
\text { 2nd Testing }\end{array}$ \\
\hline $\begin{array}{l}18 \text { " improving", } \\
19 \text { " unchanged " or " worsening " }\end{array}$ & $\begin{array}{l}\cdots \\
\cdots\end{array}$ & $\begin{array}{l}98 \cdot 8 \\
97 \cdot 6\end{array}$ & $\begin{array}{l}100 \cdot 1 \\
100 \cdot 3\end{array}$ & $\begin{array}{r}106 \cdot 7 \\
94 \cdot 1\end{array}$ & $\begin{array}{r}105 \cdot 6 \\
88 \cdot 4\end{array}$ \\
\hline
\end{tabular}

Tests. - These were the same as described in the previous paragraphs. The battery of tests was given individually to the patients and repeated approximately two years later (23.4 months on the average) under identical conditions and by the same psychologist. No well established norms exist for the memory and fluency tests, so it is impossible to ascertain whether or not improvement, if any, on these tests is in line with normal expectations. Comparison results on test and re-test will be limited to the Progressive Matrices and Mill Hill Vocabulary Tests.

Results.-These were analysed under two headings, whole group and medical categories.

Whole Group.-The percentile scores on the progressive matrices were transformed into I.Q. terms. On the second testing, as is to be expected, the average I.Q. is slightly higher than on the first testing : the average on first testing was 97.2 and on the second testing $99 \cdot 2$. There was very great individual variation from first testing to second : 22 patients varied more than 5 points of I.Q. ; 10 more than 10 points. Using Raven's suggested grades, it was found that the correlation between
18 patients were unchanged, 13 were one grade down, six were one grade up, and two were two grades up. The correlation between grade on first testing and grade on second testing is $\mathbf{0 \cdot 8 2}$.

Medical Categories.-With regard to their clinical progress, 18 were considered to be improving, that is having fewer attacks, 16 unchanged, and three were somewhat worse (two had left the clinic). As the "worsening" group was so small it was decided to put the " unchanged" and "worsening" groups together for comparison with the "improving" group. The comparative results on the first and second testings for the Progressive Matrices Test and Mill Hill Vocabulary Test are shown in Table II.

On the Progressive Matrices Test there is little difference between the two groups in average I.Q. at first testing, but the "improving" group on second testing show somewhat less improvement than the "unchanged" or "worsening" group. Neither difference is significant. On the Mill Hill Vocabulary Test the " unchanged " or " worsening" group is initially well below the "improving" group, and there is only a slight fall in the "improving" group at the second testing while the other 
group is significantly lower on the second testing than on the first. The two subjects who showed an increase of two grades in the vocabulary test were both " improving" cases.

It has sometimes been suggested that different types of epileptic attacks are correlated with different degrees of deterioration. The data from this investigation were analysed to discover whether or not they would show a differential change for the various types, and a summary is given in Table III. education was proceeding normally during the interval between testings and six where it was interrupted to some extent. In Table IV are set out the average quotients on the two main tests for the first and second testing for the two groups.

At the first testing the two groups show large average differences in both verbal and non-verbal intelligence. At the second testing those whose education has been irregular drop over 4 points in I.Q. on progressive matrices, but the difference is

TABLE III

RESULTS ON FIRST AND SECOND TESTING FOR PROGRESSIVE MATRICES AND MILL HILL VOCABULARY TESTS ACCORDING TO DIFFERENT TYPES OF ATTACKS

\begin{tabular}{|c|c|c|c|c|c|c|}
\hline $\begin{array}{l}\text { No. of Cases and } \\
\text { Type of Attack }\end{array}$ & & & $\begin{array}{l}\text { Average I.Q. } \\
\text { 1st Testing }\end{array}$ & $\begin{array}{l}\text { Average I.Q. } \\
\text { 2nd Testing }\end{array}$ & $\begin{array}{l}\text { Average V.A.Q. } \\
\text { 1st Testing }\end{array}$ & $\begin{array}{l}\text { Average V.A.Q. } \\
\text { 2nd Testing }\end{array}$ \\
\hline $\begin{array}{l}8 \text { with minor } \\
20 \text { with major } \quad \cdots \\
11 \text { with major and minor }\end{array}$ & $\begin{array}{l}\cdots \\
\cdots \\
\cdots\end{array}$ & $\begin{array}{l}\cdots \\
\cdots \\
\cdots\end{array}$ & $\begin{array}{l}99 \cdot 0 \\
96 \cdot 1 \\
97 \cdot 9\end{array}$ & $\begin{array}{r}97 \cdot 9 \\
98 \cdot 8 \\
100 \cdot 8\end{array}$ & $\begin{array}{r}112 \cdot 5 \\
96 \cdot 7 \\
94 \cdot 4\end{array}$ & $\begin{array}{r}103 \cdot 5 \\
92 \cdot 7 \\
94 \cdot 7\end{array}$ \\
\hline
\end{tabular}

TABLE IV

RESULTS ON FIRST AND SECOND TESTING FOR PROGRESSIVE MATRICES AND MILL HILL VOCABULARY TESTS OF PATIENTS WITH NORMAL AND INTERRUPTED EDUCATIONS

\begin{tabular}{|c|c|c|c|c|}
\hline No. of Patients & $\begin{array}{l}\text { Average I.Q. } \\
\text { 1st Testing }\end{array}$ & $\begin{array}{l}\text { Average I.Q. } \\
\text { 2nd Testing }\end{array}$ & $\begin{array}{l}\text { Average V.A.Q. } \\
\text { 1st Testing }\end{array}$ & $\begin{array}{l}\text { Average V.A.Q. } \\
\text { 2nd Testing }\end{array}$ \\
\hline $\begin{array}{l}6 \text { patients with interrupted education.. } \\
24 \text { patients with normal education }\end{array}$ & $\begin{array}{r}93 \cdot 8 \\
103 \cdot 0\end{array}$ & $\begin{array}{r}89 \cdot 5 \\
104 \cdot 5\end{array}$ & $\begin{array}{r}92 \cdot 3 \\
108 \cdot 2\end{array}$ & $\begin{array}{r}85 \cdot 7 \\
106 \cdot 8\end{array}$ \\
\hline
\end{tabular}

On the progressive matrices none of the differences between first and second testings is statistically significant. On the Mill Hill Vocabulary Test the whole group shows a tendency to a lower V.A.Q. on re-testing, but when the results are subdivided according to kind of epilepsy it is apparent that it is those with minor attacks who show this most markedly. This difference, however, does not quite reach the level of statistical significance.

For comparison with the results given in Table II it might be noted that of the eight patients with minor attacks six are reported to be "improving", one has left the clinic, and one has shown no change.

Educational Facilities. - Of the group of 39, two were no longer attending the clinic and information as to their education was not available. Only eight of the remaining 37 had their education interrupted due to their attacks. Two of these were past school age when the second testing was done, and so the previous interruption in their education could have no bearing on the difference between their vocabulary rating at the two testings. Of the 29 patients known to have had no interruption in their education, five were over school age at the time of their second testing, leaving 24 cases where not significant. On the vocabulary test those whose education has been interrupted drop nearly 7 points in V.A.Q. and this difference is statistically significant.

The correlation between grade on the progressive matrices for the first and second testing is 0.76 . The reliability of this test is usually found to be somewhat lower than that of verbal intelligence tests, namely about $\mathbf{0 . 8 5}$. It is to be expected that with an interval of two years between the testings the correlation will be rather lower. Keir (1949) reported a correlation of 0.64 between successive trials by a small group of 11-year-old children with an interval of two years between testings. The author (1945), using only the board form of the test on a group of 84 senile dementia patients, reported a reliability coefficient of 0.49 when the second trial was made four months after the first. It would appear that the correlation of 0.76 between successive trials by the epileptic patients with an interval of two years is not abnormal.

The correlation between grade on the Mill Hill Vocabulary Test for first and second testing was found to be $\mathbf{0} \cdot 82$. This would seem to be rather low for this test even with an interval of two years. For 
comparison it is interesting to note that the author (1945) reported a reliability coefficient of 0.96 for this test when given to senile dementia patients with an interval of four months. The unusually low correlation found for the epileptic patients suggested that it might be worthwhile analysing the results in greater detail.

When the results of test and re-test are studied separately for the patients reported as " improving" and those reported as " unchanged " or "worsening ", it is found that the drop in vocabulary quotient for the "unchanged" and "worsening" group is statistically significant. Taking the patients with each type of epileptic attack separately, it is found that none of the differences reaches the level of statistical significance. The group suffering from minor attacks shows the largest drop in vocabulary. (The probability of this difference being due to chance is 1 in 10.) Lennox (1944) reported that " cases with pure petit mal may go unscathed" as regards deterioration. The number of patients of this type in this investigation is too small for the suggestive deterioration in vocabulary rating to be regarded as a serious refutation of his findings, but it would be interesting to know what further research could discover in this matter of differential deterioration of the various epileptic types.

The patients whose education has been interrupted show a significant fall in vocabulary quotient. This result would seem to suggest that being kept from school because of their attacks has meant that there has been a serious retardation in the normal rate of vocabulary growth.

None of the differences found between test and re-test on progressive matrices is statistically significant.

\section{Comparison of 57 Epileptic Children with a Control Group}

Population.-Fifty-seven epileptic children were investigated, this being the total group of 7- to 14-year-old children diagnosed as suffering from idiopathic epilepsy with an I.Q. 75 or over on the progressive matrices who were given all the tests.

Tests.-The battery of tests as described previously had been given to the 57 epileptic children, and the same tests were given to the control group*, matched one to one for sex, for age within three months, and as nearly as possible for score on the progressive matrices.

Results.-The chief purpose of this investigation was to discover whether or not any differences would be found between epileptic and normal children, matched for age, sex, and non-verbal

\footnotetext{
* Miss S. Rostal was good enough to do the matching and testing of the control group.
}

intelligence, in other mental abilities, as measured by the memory tests, fluency tests, and vocabulary.

The average age of the epileptic group and the normal group was identical, but despite time and care in matching the matrices score the control group had nearly one point lower score on the average, which fact should make somewhat more significant any superiority shown by the controls over the epileptics on the other tests.

The scatter was calculated for each child's score on the progressive matrices, Raven's suggestion being that a high scatter is indicative of a rather lower reliability. ("Scatter" is the sum of the differences between the child's score on each of the five separate sets and the median scores made by subjects whose total score on the whole test is identical.) The average scatter for the controls was 3.5 and for the epileptics 3.0 , indicating that the epileptics' scores were possibly slightly more reliable. This difference does not reach the level of statistical significance. A much larger difference appears on the time taken to complete this test : the average time spent by the controls was 16.7 minutes and by the epileptics 21.3 minutes. This difference is statistically significant but too much stress cannot be placed on it, for it is undoubtedly possible that the time taken on an individual test of this type is as much due to the tester as to the child.

With regard to the results of the test of retentivity (memory), the group of 57 control children recalled on the average 24.9 items immediately after learning and the epileptic children 23.8 items. This difference is not significant. When asked again at the end of the testing session to recall the items the controls produced 18.6 items and the epileptics $16 \cdot 0$. This difference also fails to reach the level of statistical significance.

With regard to the fluency test results, the pattern is reversed. The total scores on the two tests of naming flowers and birds were taken together as "reproductive fluency" and those on the two tests of giving possible items under the tree and in the street together as " imaginative fluency". Here the epileptics showed a superiority : for " reproductive fluency" their average was 16.3 and the controls' average was $15 \cdot 1$; for "imaginative fluency" the epileptics' average was $18 \cdot 1$ and the controls' was 14.0 . The difference in "reproductive fluency" is not significant, but the difference in "imaginative fluency" is statistically significant.

Again, in the scores on the vocabulary test the epileptic group showed a small superiority. Their average score was 27.0 and the controls' average was $25 \cdot 7$. This difference is not statistically significant. 
Somerfeld-Ziskind and Ziskind (1940) found that epileptics are defective in memory retention, and this would seem to be a widely accepted belief. In the present investigation the difference in immediate memory between the epileptic children and the control group is below the level of statistical significance, and the difference in delayed recall, while somewhat larger, fails to reach the level of significance. (The probability of its being due to chance is 1 in 10.) These results, therefore, would seem to lend little support to the view that epileptics are particularly poor in memory. It is also to be remembered that all the epileptic children were being treated with anti-convulsants.

Capps (1939) and also Somerfeld-Ziskind and Ziskind (1940) mention a general defect in language ability among epileptics, but the results reported here do not bear this out. In the fluency tests and in the vocabulary, test the advantage lies with the epileptics, but the only difference to reach the level of statistical significance is the one in "imaginative fluency". The explanation of this superiority on the part of the epileptics in these language tests may be twofold : the epileptics' very small advantage in non-verbal intelligence, and the probably slightly better social and cultural background of the epileptic group compared to the controls who lived in a crowded south London borough. In addition it is not known what the effect on the results may be from having two different testers, though care was taken to try to ensure that identical instructions and encouragement were given, and the author scored the responses of both groups.

\section{Summary and Conclusions}

The average intelligence of a group of 161 epileptic patients is only slightly below normal : median I.Q. is 94 on the Progressive Matrices Test and the median V.A.Q. is 96 on the Mill Hill Vocabulary Test.

The distribution of gradings on the Progressive Matrices Test of the epileptic patients differs significantly from that of a normal population.

Over $12 \%$ of the 161 epileptic patients are below the level of mental deficiency on both the verbal and non-verbal test.

A group of 19 patients whose condition is considered " unchanged" or "worse" show a significant fall in vocabulary quotient on re-testing after an interval of two years : 18 patients whose attacks are decreasing show no significant fall.

Epileptic patients with minor attacks show a larger fall in vocabulary quotient on re-testing than those with major or major and minor attacks but none of the differences is significant.

Patients whose education has been interrupted due to epilepsy show a significant fall in vocabulary quotient on re-testing.

No group of epileptic patients shows a significant change in progressive matrices quotient on retesting.

A group of 57 epileptic children, matched for sex, age, and score on progressive matrices score with a control group, shows a lower scatter of scores on separate sets of progressive matrices. This difference is suggestive of somewhat greater reliability but is not statistically significant.

The epileptic children took longer to do the Progressive Matrices Test than the control group. This difference is statistically significant but it is possible that part of the difference is due to the fact that two different testers administered the tests.

The epileptic children's inferiority in immediate memory is not significant, and their inferiority in delayed recall, while somewhat greater, is below the level of statistical significance.

The epileptic children are superior in both fluency scores : in " reproductive fluency" the difference is not significant but in " imaginative fluency" it is statistically significant.

The epileptic children show no significant difference in vocabulary.

The London County Council was kind enough to arrange facilities for testing a control group of normal children in three schools, and my thanks are due to the Education Officer of the L.C.C. and to the head teachers of the Oliver Goldsmith Junior Mixed School, Albany Road Secondary Girls' School, and Southampton Way Secondary Boys' School for their courtesy and helpfulness.

\section{REFERENCES}

Arluck, E. W. (1941). Arch. Psychol., N.Y., No. 263. Capps, H. M. (1939). Ibid., No. 242.

Cattell, R. B. (1936). "A Guide to Mental Testing." London.

Eysenck, M. D. (1945). Journal of Neurology, Neurosurgery and Psychiatry, 8, 15.

Keir, G. (1949). Brit. J. Psychol. (Stat. Sect.), 2, 140.

Lennox, W. G. (1944). In "Personality and the Behaviour Disorders," ed. by J. McV. Hunt, vol. 2, ch. 31, pp. 938-967. New York.

764 .

Sheps, J. G. (1947). J. ment. Sci., 93, 82.

Somerfeld-Ziskind, E. and Ziskind, E. (1940). Arch. Neurol. Psychiat., Chicago, 43, 70.

Sullivan, E. B., and Gahagan, L. (1935). Genet. Psychol. Monogr., 17, 309. 